\section{ANNUAL MEETING OF CHINESE SCIENTIFIC SOCIETIES}

JOINT annual meeting of the Science Society, the Zoological Society, the Botanical Society, the Meteorological Society, the Mathematical Society and the Geographical Society of China was held at Pehpei, Chungking, during July 18-20 of last year. Despite the hot weather which prevailed then, 240 members attended the meeting, which was presided over by Dr. Wong Wen-hao. In his opening address, Dr. Wong said that a joint meeting like this is especially desirable in war-time, in that it is economical in time, labour and expenditure and will enhance co-operation between societies which are related in character. In view of the present tendency to overlook the study of pure science, Dr. Wong remarked that truth is what science values most, regardless of whether or not practical use can be derived from it; and he urged the pure scientists to stand firm. As a geologist and the Minister of Economic Affairs, he illustrated with first-hand examples how what appeared to be pure geology at first turned out later to be of much practical value in the detection of China's natural resources. The address of the Generalissimo was then read, in which he declares: "Pure science is the foundation of all applied sciences. If we wish to stand up among the modern great nations there must not be the slightest tardiness in the prosecution of pure science" (see also Nature, Aug. 14, 1943, p. 180). While most of the official emphasis has been laid on the practical side in the recent tide of national industrialization, it will do the nation good to remind people of the significance of pure science.

In the business meeting held in the first afternoon, Dr. J. Needham was elected honorary member of the Science Society of China, in appreciation of his distinguished academic work and his service in promoting co-operation between Chinese and Western science, which had been so effectively carried on during the previous six months.

The six societies spent two mornings in communicating original papers dealing with their respective sciences; more than three hundred papers were read. Brief abstracts of these papers will be published shortly, in Chinese with additional English titles.

One of the two remaining afternoons was devoted to a discussion on "Science and National Reconstruction", with special reference to the problem of how science is to be promoted in China. Opinions were formulated on the following four points, which were presented to the Chinese Government for immediate adoption.

(1) The Government is requested to provide a large fund in the forthcoming national budget for, and only for, the furtherance of scientific research and of the scientific education of the masses.

(2) The personnel and equipment of the leading science institutes, such as those of Academia Sinica, must be materially augmented.

(3) The Government must endeavour to establish co-operation between the scientific workers on one hand and officials in charge of national planning on the other, so that the resulting plans may be more practical and fruitful.

(4) While the Government is considering sending a large number of young. men of science abroad, it is deemed appropriate that such opportunities should be extended to mature scholars also. Here again, the
Government is requested not to neglect pure science in favour of applied sciences and technology.

The last afternoon of the meeting was reserved for a discussion on "International Science Co-operation". To familiarize the audience with some idea of the subject under discussion, four specialists were asked to talk about the co-operative measures hitherto taken, along with the sound results accomplished therefrom, in agriculture, industry, meteorology, and medicine and public hygiene. Dr. Needham's address, entitled "International Science Co-operation in War and Peace", was read next by Dr. H. C. Zen, president of the Science Society of China. In this address, Dr. Needham reviewed the present position of cooperation between Chinese and Western science and the problems arising on the scientific side of the war effort of the United Nations in the Asiatic theatre; he urged, above all, that a science co-operation service should be made a regular part of the United Nations Relief and Rehabilitation Administration. The meeting was unanimous that international science co-operation, founded on international understanding and goodwill, is worthy of striving for. Indeed, Chinese men of science seek co-operation with no less enthusiasm than their friends of the West.

A scientific exhibition intended for the general public has been arranged by the learned societies of China during the present session.

\section{DIRECTIVE AERIALS FOR RADIO COMMUNICATIONS}

$T$ HE second discussion evening of the current session of the Wireless Section of the Institution of Electrical Engineers was held on January 18, when Mr. J. A. Smale introduced the subject of "Comparative Merits of Different Types of Directive Aerials for Communications". At the outset, it was made elear that the main objects of using directive aerials are to increase the field strength of the signal at the receiving station without increasing the power radiated by the transmitter, and to improve the ratio of signal to noise and interference at the receiving site; another desirable aim is to minimize interference with other users of the ether.

In long-distance communication, interest is confined mainly to wave-lengths between 13 and 100 metres ; the maximum obtainable gain, in general, requires one linear horizontal dimension of some 10 wave-lengths, and, while this is realizable up to about 30 metres, it tends to impracticability at the upper end of the-wave-length range. In the above range of wave-lengths, transmission is effected by one or more reflexions from the ionosphere, the characteristics of which give to the ray paths various degrees of inclination in the vertical plane. Consequently, aerials have to possess directivity in this as well as in the horizontal plane, and in some types these two directivities are dependent on one another.

The two main aerial systems used are of the broadside and linear or end-fire types. In general, the endfire type have their horizontal and vertical directivities interdependent; the maximum concentration in the horizontal plane results in very low angles of radiation in the vertical plane, so that for shortdistance circuits requiring higher angles no satisfactory compromise is possible. In the case of broad. 